\title{
A comparative approach to computer aided design model of a dog femur
}

\author{
O. Turamanlar ${ }^{1}$, O. Verim² ${ }^{2}$ A. Karabulut ${ }^{2}$ \\ ${ }^{1}$ Department of Anatomy, Faculty of Medicine, Afyon Kocatepe University, Afyonkarahisar, Turkey \\ 2Department of Mechanical Engineering, Faculty of Technology, Afyon Kocatepe University, Afyonkarahisar, Turkey
}

[Received: 8 March 2016; Accepted: 15 April 2016]

\begin{abstract}
Computer assisted technologies offer new opportunities in medical imaging and rapid prototyping in biomechanical engineering. Three dimensional (3D) modelling of soft tissues and bones are becoming more important. The accuracy of the analysis in modelling processes depends on the outline of the tissues derived from medical images. The aim of this study is the evaluation of the accuracy of $3 D$ models of a dog femur derived from computed tomography data by using point cloud method and boundary line method on several modelling software. Solidworks, Rapidform and 3DSMax software were used to create 3D models and outcomes were evaluated statistically. The most accurate 3D prototype of the dog femur was created with stereolithography method using rapid prototype device. Furthermore, the linearity of the volumes of models was investigated between software and the constructed models. The difference between the software and real models manifests the sensitivity of the software and the devices used in this manner. (Folia Morphol 2016; 75, 4: 550-554)
\end{abstract}

Key words: dog femur, iterative closest point algorithm, rapid prototype, root mean square, three dimensional modelling

\section{INTRODUCTION}

The advancements in computer engineering bring up the usage of computer software for computer aided design (CAD) and analysis in medical purposes. In this manner the area has a wide perspective such as virtual clinical treatments, implant design and prosthesis production $[5,12]$. The main aim in modelling the tissues in CAD software is to convert the 2 dimensional (2D) radiographic images to the 3 dimensional (3D) models for the preparation and the planning of complicated surgical operations. CAD software makes it possible to examine complicated damages on the tissues from tomography and magnetic resonance imaging radiographies.

Many 3D matching methods had been utilised for the implementation of radiographic images to their real models. One of the most frequently used numerical matching methods is iterative closest point (ICP) method. ICP algorithm was used by Besl and McKay for the resolution of free form surface match problems $[1,3,6,10,14]$. Oka et al. [8] analysed the matching sensitivity of models with their radiographic images gathered by using low and normal radiation dosages. Afterwards the images were tested with the data gained coordinate measuring machine and researchers reported that they obtained standard error between models. Gelaude et al. [4] worked on the radiographic images on bones segments for the determination of error sensitivity within their studies.

Researchers developed rapid prototype and manufacturing (RPM) techniques for custom made implant production for patients [2]. By means of RPM, physical model copies are possible to be made from complex $3 D$ images. Data derived by the aid of CAD software

Address for correspondence: Dr. O. Turamanlar, MD, PhD, Department of Anatomy, Faculty of Medicine, Afyon Kocatepe University, 03200, Afyonkarahisar, Turkey, tel: +90-272-2463304, fax: +90-272-2463300, e-mail: ozanturamanlar@hotmail.com 


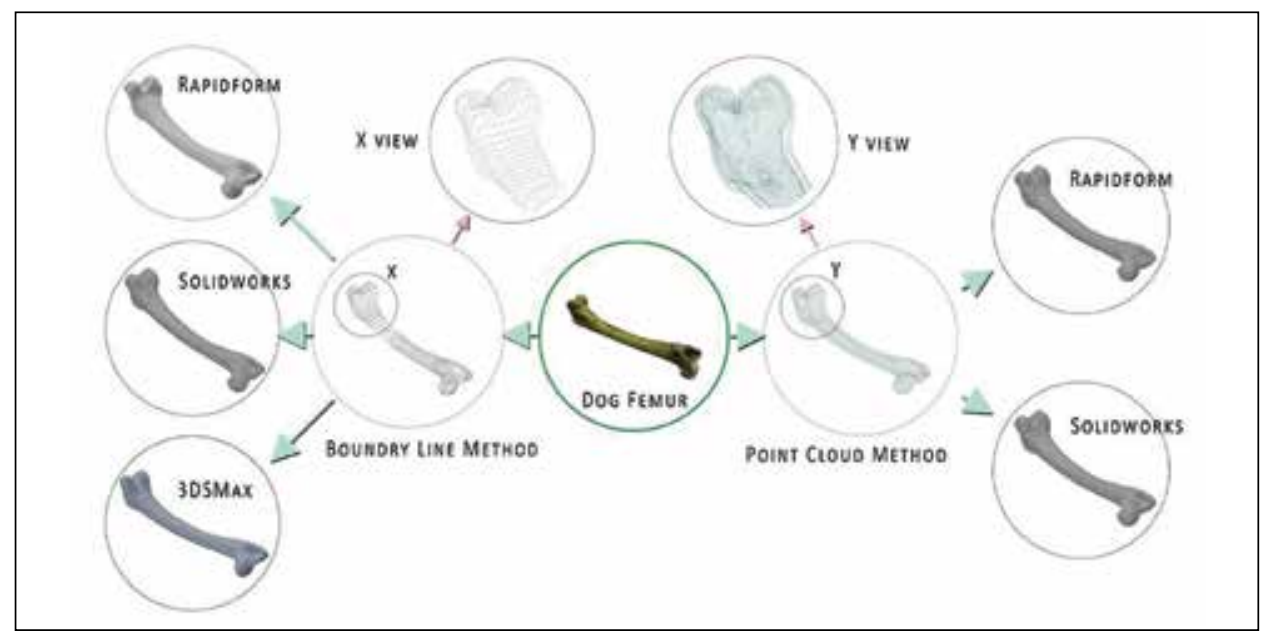

Figure 1. Modelled images formed by using point cloud method and boundary line method.

are held on Rapid Prototyping (RP) system to produce the required parts in desired shape and accuracy. In this study, three different CAD software were used to create $3 D$ models from $2 D$ images obtained by computed tomography (CT) and results were evaluated statistically.

\section{MATERIALS AND METHODS}

\section{Three-dimensional reconstruction of dog femur}

A preserved dog femur from Anatomy Department of Veterinary Faculty of Afyon Kocatepe University was used in this study. Radiographic $512 \times 512$ pixel resolution images were acquired using SIEMENS-Sensation 40 computerised tomography and device adjustments were set to $120 \mathrm{KV}$ and $65 \mathrm{mAs}$ for radiographic quality. A total of 494 images were acquired at the slice thickness of $0.4 \mathrm{~mm}$ and a software tool was used for $3 \mathrm{D}$ reconstruction of the tissues. The images were handled in a frequently used medical image format "Dicom" and automatic segmentation process was made in Mimics software. An initial virtual bone models were derived by using a 260 Hounsfield (HU) lower limit threshold for highlights. The dosing for radiation was calibrated for every CT procedure individually depending on bone HU measurements. The modelled structures were optimised using Remesh plug-in of Mimics (Materialise, Leuven, Belgium). Models were then transformed into NonUniform Rational Basis Splines (NURBS) surface format using point cloud method (PCM) and boundary line method (BLM). The data were transferred to CAD software; Solidworks (DassaultSystems), Rapidform
(INUS Technology, Korea) and 3DSMax (Autodesk, Inc.). The results of methods and transferred data were shown on Figure 1.

As shown in BLM, three different software were used to create 3D models by the aid of interpolations between sectional splines which were longitudinal to the direction of the bone axis (Fig. 1). In PCM, two different software were used to create NURBS surfaces trough point cloud data. The PCM was used only with Solidworks and Rapidform software which were the one only to have automatic surface scanning property.

In this study, the accuracy of the created surfaces were determined by visual precision and later quantified by root mean square (RMS) measurements. Rapidform software was used for 3D/3D matching method in this study. Rapidform is a powerful software that has registration accuracy. Three different software models of a dog femur were created and then transferred into Rapidform. Surface-to-surface matching method was utilised for the models by using ICP algorithm (Fig. 2). Analysis values of matching accuracy of the models were represented in Table 1.

\section{Prototyping and manufacturing of the dog femur}

In recent years, rapid prototyping techniques and traditional scaffold fabrication methods are used in tissue engineering frequently. RP technologies are the general naming of the advanced production procedures based on level-by-level addition of material for the production of complex structures [9]. All RP procedures were depended on the CAD data transferred in. STL file format which is kept as golden standard in industry. Many RP techniques were de- 


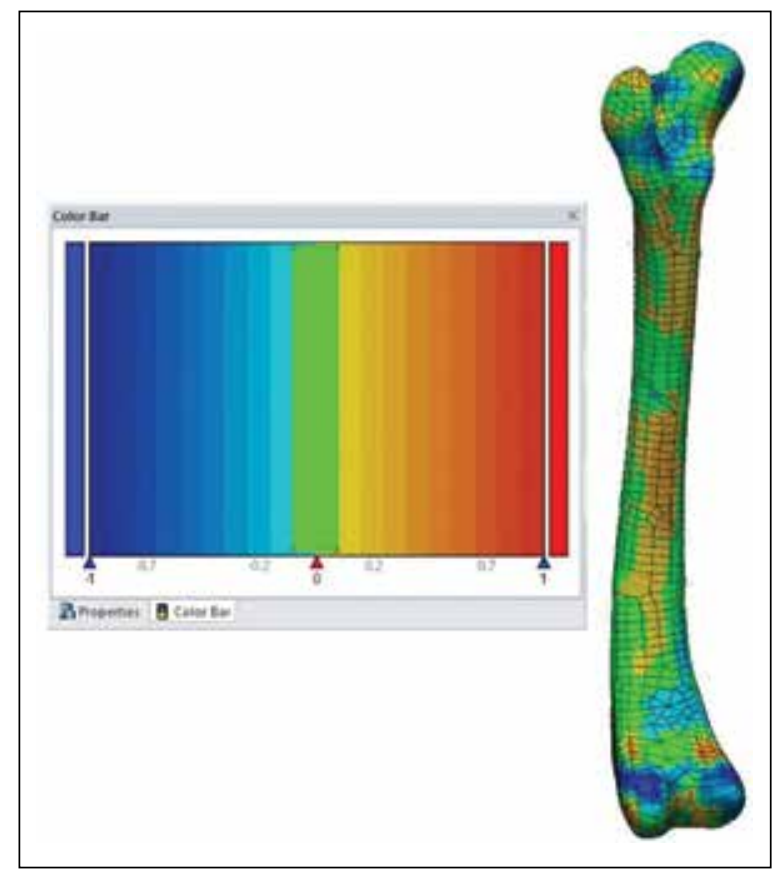

Figure 2. Accuracy analysis of dog femur in Rapidform.

veloped and commercialised in recent years. Fundamentally, the lamination methods work on three bases: liquid, solid and dust. Liquid based technology involves stereolithography (SLA) and double photon polymerisation. Whereas solid based comprises fused deposition modelling, dust method has selective laser sintering and 3D printing techniques $[7,9,15,16]$. Today, new technologies are developed day by day. In this study, SLA method was used for the production of dog femur (Fig. 3).

In SLA method, UV rays are used on photo polymer liquid for the formation of the structure. The procedure is done layer by layer. In these methods, the surface of a model forms a wavy surface therefore the smoothness and the accuracy of the model

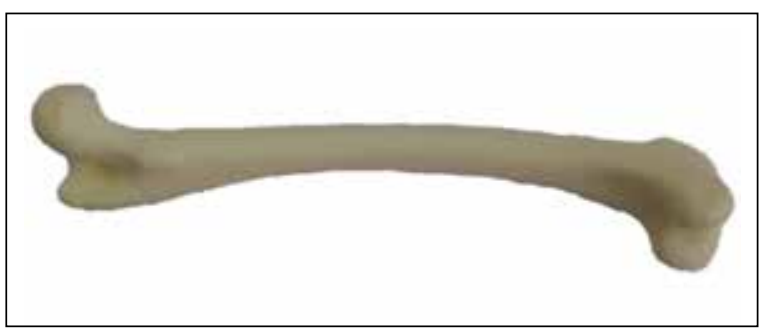

Figure 3. The dog femur produced with using stereolithography method.

are affected negatively. Under this scope, choosing a manufacturing method become more important.

\section{RESULTS}

In engineering area the issue of determining the volume, mass properties and the centre of gravity is important for many reasons. In addition to this, created models supply surface area information and the relative connections, solid models provide a slice cut view within a determined direction. Volume information is important for the design and the production of individually made implants for patients. When the volume or weight of a tissue is needed to a surgeon, solid designs are optimal for this purpose.

When the visual quality of the model taken into consideration, 3DSMax is a bit further beyond than other software due to its powerful rendering processes. However a structural deficit exists in 3DSMax for measured modelling processes by missing parametrical design function therefore it is not used. Solidworks and Inventor software are based on parametric design therefore used in industry frequently. Along with these, Rapidform is also used for reverse engineering both with parametric design which is also kept as a professional designer available. Along with two methods and three different software six

Table 1. Results of statistical analysis of the 3D dog femur models

\begin{tabular}{lccccc}
\hline & Software & Volume $\left[\mathrm{mm}^{3}\right]$ & RMS $[\mathrm{mm}]$ & SD [mm] & Accuracy rate [\%] \\
\hline Boundary line method & Solidworks & 46823 & 0.231 & 0.226 & 88.3 \\
& Rapidform & 46527 & 0.240 & 0.246 & 88.9 \\
& 3DSMax & 45346 & 0.300 & 0.302 & 91.2 \\
\hline Point cloud method & Solidworks & 45290 & 0.002 & 0.002 & 91.3 \\
& Rapidform & 45169 & 0.001 & 0.001 & 91.6 \\
\hline SLA model & - & 45668 & - & - & 90.6 \\
\hline Real model & - & 41387 & - & - & 100 \\
\hline
\end{tabular}

RMS — root mean square; SLA — stereolithography; SD — standard deviation 
varying models were obtained. The statistical values of the models can be seen in Table 1. The surface area and RMS values were given with volumetric analysis.

In the created models by varying software, the lesser RMS values mean the more accurate models and more identical to their real matches. The RMS values were obtained in Rapidform software by using ICP algorithm. By the means of the gathered values of this study, the PCM was found to be more accurate compared with BLM. The RMS values of the models created by using PCM were much smaller compared with BLM. In BLM, models are created by using point cloud and density of the points determines the accuracy of the surface of the model. The boundary line modelling in BLM requires many depictions of guide lines to increase the accuracy of the surface of models. Yet this depiction may not be convenient for every complex geometrical shape.

\section{DISCUSSION}

Tolouei-Rad [13] compared models created by varying software by means of surface analysis. The result of the study made by Tolouei-Rad [13] was suggested that the software choice must be tailored to the needs individually. In the study of Starly et al. [11] researchers were evaluated the assessments on the creation stages of a 3D model and they found that reverse engineering gave better results compared with other software.

In our study, the real volume of the investigated dog femur was found to be $41387 \mathrm{~mm}^{3}$ in lab conditions using Archimedes principle. When the relation of volumetric analysis taken into consideration, it can be seen that the model created by Rapidform using PCM was more eligible. The accuracy rate between two models was found as $91 \%$ within evaluations. Following these, a real model was created with SLA method and volume of this model was found as $45668 \mathrm{~mm}^{3}$. The relation between real volume of dog femur and reproduced copy was found in $90.6 \%$ accuracy (Table 1 ).

\section{CONCLUSIONS}

The creation of 3D tissues eases the surgeon's practices for the treatment of patients. Therefore, it is more important to create accurate models. In this study, three different software were used to create bone models and the geometrical and statistical relations of the created models were evaluated. In this respect, Rapidform as a reverse engineering software was found more efficient by means of RMS, volume and standard deviation compared with other software. In addition to these, PCM was found to be more convenient in 3D modelling processes. As it can be seen in Table 1, the values obtained from parametrical design software were found close to each other. The advanced modelling processes of software can be the reason for the close relationship of these values. One another important issue is production methods in as much as modelling. Rapid prototype was found accurate, economic and rapid therefore in this manner it is found as commercially favourable.

\section{Acknowledgements}

The authors would like to thank Afyon Kocatepe University, Veterinary Anatomy Department employees for supplying the study material.

\section{REFERENCES}

1. Besl PJ, McKay N (1992) A Method for Registration of 3-D shapes. IEEE Trans Pattern Anal Mach Intell, 14: 239-255.

2. Chelule KL, Coole T, Cheshire DG (2000) Fabrication of medical models from scan data via rapid prototyping techniques. Proceeding of TCT (Time-Compression Technologies) 2000 Conference and Exhibition, UK, 45-50.

3. Denis K, Van Ham G, Vander Sloten J, Van Andekercke R, Van der Perre G, De Schutter J, Fabry G (2003) Registration of the tibia in robot-assisted total knee arthroplasty using surface matching. International Congress Series, 664-669.

4. Gelaude F, Vander Sloten J, Lauwers B (2008) Accuracy assessment of CT-based outer surface femur meshes. Comp Aid Surg, 13: 188-199.

5. Hollister SJ, Levy RA, Chu TM, Halloran JW, Feinberg SE (2000) An image-based approach for designing and manufacturing craniofacial scaffolds. J Oral Maxillofac Surg, 29: 67-71.

6. Kubota Y, Sakamoto M, Kobayashi K, Koga Y, Tanabe Y (2010) Accuracy verification of image-matching in a setting method for the stem during total hip arthroplasty. JSEM, 10: 247-250.

7. McGurk M, Amis AA, Potamianos P, Goodger NM (1997) Rapid prototyping techniques for anatomical modelling in medicine. Ann R Coll Surg Engl, 79: 169-174.

8. Oka K, Murase T, Moritomo H, Goto A, Sugamoto K, Yoshikawa $\mathrm{H}$ (2009) Accuracy analysis of three dimensional bone surface models of the forearm constructed from multidetector computed tomography data. Int J Med Robotics Comput Assist Surg, 5: 452-457.

9. Peltola SM, Melchels FP, Grijpma DW, Kellomäki M (2008) A review of rapid prototyping techniques for tissue engineering purposes. Ann Med, 40: 268-280.

10. Rangarajan A, Chui H, Mjolsness E, Pappu S, Davachi L, Goldman-Rakic P, Duncan J (1997) A robust point-matching algorithm for auto radiograph alignment. Med Img Anal, 1: 379-398. 
11. Starly B, Fang Z, Sun W, Shokoufandeh A, Regli W (2005) Three dimensional reconstruction for medical-cad modeling, Comp Aid Des Applications, 2: 431-438.

12. Sun W, Starly B, Nam J, Darling A (2005) Bio-CAD modeling and its applications in computer-aided tissue engineering. Comp Aid Des, 37: 1097-1114.

13. Tolouei-Rad (2010) A comparative approach to modeling of hard tissues. Archives of Materials Science Engineering, 42: 119-125.
14. Verhey JF, Wisser J, Warfield SK, Rexilius J, Kikinis R (2005) Non-rigid registration of a 3D ultrasound and a MR image data set of the female pelvic floor using a biomechanical model. Biomed Eng Online, 4: 11.

15. Yan X, Gu P (1995) A review of rapid prototyping technologies and systems. Comp Aid Des, 28: 307-318.

16. Yeong WY, Chua CK, Leong KF, Chandrasekaran M (2004) Rapid prototyping in tissue engineering challenges and potential. Trends Biotechnol, 22: 643-652. 